\title{
Article
}

\section{Values-Based Practice and Reflective Judgment}

\author{
Thornton, Tim
}

Available at http://clok.uclan.ac.uk/4357/

Thornton, Tim ORCID: 0000-0002-0137-1554 (2008) Values-Based Practice and Reflective Judgment. Philosophy, Psychiatry, \& Psychology, 15 (2). pp. 125-133. ISSN 1086-3303

It is advisable to refer to the publisher's version if you intend to cite from the work. http://dx.doi.org/10.1353/ppp.0.0177

For more information about UCLan's research in this area go to

http://www.uclan.ac.uk/researchgroups/ and search for < name of research Group $>$.

For information about Research generally at UCLan please go to http://www.uclan.ac.uk/research/

All outputs in CLoK are protected by Intellectual Property Rights law, including Copyright law. Copyright, IPR and Moral Rights for the works on this site are retained by the individual authors and/or other copyright owners. Terms and conditions for use of this material are defined in the policies page.

\section{CLoK}

Central Lancashire online Knowledge www.clok.uclan.ac.uk

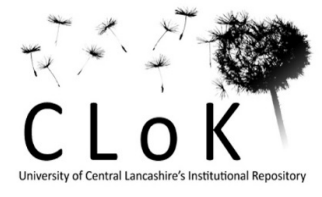


Full Title:Values based practice and reflective judgement.

Short title: Values based practice and reflective judgement.

Authors (i.e. name as it should appear on the paper):

Tim Thornton

Position (i.e. job description as it should appear on the paper):

Tim Thornton

Professor of Philosophy and Mental Health

Address for correspondence:

Institute for Philosophy, Diversity and Mental Health

University of Central Lancashire

Preston

PR1 2HE

Other Contact Details:

phone 44 (0) 1772895412

fax $44(0) 1772892964$

email:

TThornton1@uclan.ac.uk

Key-words (not appearing in title):

Idiographic judgement; empathy; tacit knowledge; determinate judgement; rule following.

Word count (excluding title page but including references):

$\sim 5,900$

Character count (abstract):

Software used: Microsoft Word

Filename(s): 


\title{
Values based practice and reflective judgement
}

\author{
Tim Thornton
}

\begin{abstract}
:
In this paper, I relate values-based practice (VBP) to clinical judgment more generally. I consider what claim, aside from the fundamental difference of facts and values, lies at the heart of VBP. Rather than, for example, construing values as subjective, I argue that it is more helpful to construe VBP as committed to the uncodifiability of value judgments. It is a form of particularism rather than principlism, but this need not deny the reality of values. Seen in this light, however, VBP is part of a broader conception of clinical judgment that can be compared with Kant's conception of reflective judgment. This is a useful way of marking similarities between a number of issues raised in philosophy, which can inform a better understanding of clinical judgment. Keywords: Idiographic judgment, empathy, tacit knowledge, determinate judgment, rule following.
\end{abstract}

\section{Introduction}

K.W.M. (Bill) Fulford's account of values-based practice (VBP) or valuesbased medicine is based on a philosophical analysis of the concept of illness initially motivated by consideration of the concept of mental illness. Arguing that illness is an essentially evaluative notion, he argues that it inherits key features of the logic of values. One important aspect of this is that where underlying values are agreed upon, judgments can be made about factual criteria. Thus, for example, factual judgments about the non-rotten condition of apples can go proxy, in many cases, for explicitly evaluative judgment about their quality. This, he argues, is why the evaluative aspects of health care can be overlooked in cases of underlying agreement of values but stand out, in psychiatry, for example, where such agreement is lacking.

VBP is an attempt to guide good medical practice on the basis of insight into the logic of values. Central in this is the assumption of a difference of kind between facts and values that echoes Hume's law denying that a normative prescription can ever be rationally derived from merely descriptive factual premises. But the charting the logic of value judgments as set out in the principles of VBP prompts the question. Are values subjective? Or are they merely uncodifiable?

In this paper, I argue that it is more helpful to construe VBP as committed to the uncodifiability of value judgments. It is a form of particularism rather than principlism, but this need not deny the reality of values. Indeed, whereas Hume's law marks the conceptual independence of normative and non-normative terms, particularism permits the idea that some value judgments are akin to judgments of fact in charting genuine features of the world.

Seen in this light, however, VBP is part of a broader conception of clinical judgment that can be compared with Kant's conception of reflective judgment. This is a useful way of marking similarities between a number of issues raised in philosophy that can inform a better understanding of clinical judgment.

\section{Ten Principles of Values-Based Practice}

VBP has been developed recently in the United Kingdom to guide clinical judgments in mental health care and also more broadly. VBP is the practical counterpart of the analysis of values in medicine proposed by Bill Fulford (Fulford 2004). The main emphasis in VBP is that clinical decision making, to the extent that it involves values, is not sufficiently guided by a framework of ethical rules and regulation, important as such a framework is, but depends also on learnable clinical skills to respond in a balanced way to a far broader range of diverse 
values. VBP thus shifts the emphasis in clinical decision making from 'right outcomes,' defined by ethical rules and regulation, to 'good process.' It provides a skills-based approach to balanced decision making where, as is often particularly the case in mental health, complex and conflicting values are in play.

A number of the key elements of the good process of VBP have been summarized by Fulford in the form of ten principles, as set out below. As will be seen, four key areas of clinical skill (awareness, knowledge, reasoning and communication) are defined by principles six to nine; but the good process of VBP also depends on recognizing the close interdependence of values and evidence (principles one to three), on patient-centered and multidisciplinary service delivery (principles four and five, respectively), and, perhaps most important of all, on a partnership approach to clinical decision making in which the locus of control shifts from outside experts (including lawyer and ethicists) to the particular individuals directly concerned in a given decision. The main principles of Fulford's VBP are set out below.

1. All decisions stand on two feet, on values as well as on facts, including decisions about diagnosis (the "two feet" principle)

2. We tend to notice values only when they are diverse or conflicting and hence are likely to be problematic (the "squeaky wheel" principle)

3. Scientific progress, in opening up choices, is increasingly bringing the full diversity of human values into play in all areas of healthcare (the "science driven" principle)

4. VBP's "first call" for information is the perspective of the patient or patient group concerned in a given decision (the "patient-perspective" principle)

5. In VBP, conflicts of values are resolved primarily, not by reference to a rule prescribing a "right" outcome, but by processes designed to support a balance of legitimately different perspectives (the "multi-perspective" principle)

6. Careful attention to language use in a given context is one of a range of powerful methods for raising awareness of values (the "values-blindness" principle)

7. A rich resource of both empirical and philosophical methods is available for improving our knowledge of other people's values (the "values-myopia" principle)

8. Ethical Reasoning is employed in VBP primarily to explore differences of values, not, as in quasi-legal bioethics, to determine "what is right" (the "space of values" principle)

9. In VBP, communication skills have a substantive rather than (as in quasilegal ethics) a merely executive role in clinical decision-making (the "how it's done" principle)

10. VBP, although involving a partnership with ethicists and lawyers (equivalent to the partnership with scientists and statisticians in EBM), puts decisionmaking back where it belongs, with users and providers at the clinical coal-face (the "who decides" principle). (Fulford 2004, 206)

In the United Kingdom, these principles or pointers to balanced decision making in mental health practice have been increasingly influential in a number of recent mental health care initiatives. One concrete instance is a training manual, published by the Sainsbury Centre for Mental Health, called Whose Values? A workbook for values based practice in mental health care (Woodbridge and Fulford 2004). That workbook in turn has been the basis for a number 
of policy, training, and service development initiatives rolled out through the UK government's Department of Health and, internationally, particularly through the World Psychiatric Association. My aim here, however, is not to look to those practical applications but to explore the underlying philosophical model of values which best fits this approach.

For this aim, three of these principles-two, five, and eight-are particularly important. They bring out the characteristic logic of values. We notice values only when they are diverse because when they are agreed they can become submerged beneath factual criteria. But when there is disagreement about values, there is no decision procedure to lead all parties to agreement. Further, insofar as principles can be used, they do not serve the role set out for them in a principles-driven account of medical ethics. What, precisely, do these claims presuppose about the nature of values? In this section, I consider three claims:

1. The irreducibility of values to facts.

2. The subjectivity of values.

3. The uncodifiability of values.

\section{The Irreducibility of Values to Facts}

Fulford's analysis requires a distinction between facts and values. The account of the dependence of factual criteria, for example, on underlying values requires a distinction between them. If the values apparently implicit in illness could be reduced in some way to facts, then the position would collapse into the purely factual view of illness put forward by biologically minded defenders, which Fulford criticizes.

There is, however, no knock-down argument for the 'values-in' view of mental illness. But two kinds of consideration support it. First, as Fulford in particular has argued, ordinary linguistic use of the concept of illness suggests a prima facie connection with values. To repeat, this can be disguised if there is sufficient agreement about the values involved to permit a kind of factual shorthand. But that does not undermine the fundamental priority of the value-laden concept of illness over whatever factual criteria can contingently be used to label particular illnesses.

Second, the opposing program aiming to show how apparent values can in fact be reduced to underlying facts faces grave difficulties. The most promising approach is via the concept of biological or natural function. The idea is that illness (or perhaps disease, disorder, or dysfunction) can be defined as a failure of biological function and that that in turn can be specified using purely descriptive evolutionary biological analysis (Wakefield 1999). The challenge it faces is two-fold, however.

First, it is by no means clear that selecting particular functional explanations from the full and complex history of biological happenings is just a matter of description (Fulford, 1999; Thornton 2000). Second, even if that were possible, the connection between illness and failure of function is not straightforward. There might be many cases where the dispositions and functions of a biological system do not coincide without this being the effect of any illness. (The human eye was, presumably, not selected for its blind spot-having a blind spot is not part of its function but one of its dispositions, given its biological engineering limitations-but having that blind spot is not a form of universal illness.)

On the assumption, therefore, that values are irreducible to facts, what else about them is presupposed?

\section{The Subjectivity of Values}

One possibility is the claim that values are subjective. This fits and helps to explain the irreducibility thesis. If values are subjective, then they belong to a different ontological kind 
from facts and hence cannot be reduced to them. There are a number of different ways in which this basic claim can be articulated within a broader theory of values, many deriving from the work of David Hume. The starting point for neo-Humeanism is that values are not part of the fabric of the world but are instead projected onto it as a result of the inner sentiments we feel. Whatever the details, the fundamental assumption that values do not form part of the fabric of the world provides an ontological or metaphysical explanation of the irreducibility thesis. Values are irreducible to facts because the former are subjective and the latter are objective.

The claim that values are subjective would also fit a claim from the framework of VBP set out. According to it, even ethical reasoning (not just reasoning about personal values and preferences) aims to explore differences of values rather than, as in quasi-legal bioethics, to determine what is right. A subjective view undermines the possibility of a definitive end point and hence puts the emphasis on the exploratory processes instead.

Despite the attractions of the view that values are subjective, there are two disadvantages with it. The first is a practical point. Although some value judgments appear to be subjective, others do not. The moral repulsion felt by most people over the murders committed by the UK general practitioner Harold Shipman suggests, prima facie, a deeper disagreement. It is not merely that Shipman had a legitimately different preference when it came to the relation between general practice and murder.

The second is a philosophical point. The theory that moral judgments are based on projections of inner sentiments requires a separation of complex judgment into two factors: real and objective features of the world, on the one hand, which prompt inner sentiments and attitudes, on the other. Moral reactions, on which moral judgments are based, are explained by the interplay of these two factors. (The view contrasts with a form of moral realism in which there is one explanatory factor in play: Judgments depend on reactions to worldly but also evaluative features.) The challenge for the kind of subjectivism under consideration is to give a non-question-begging account of the two factors. Neither seems to be an unproblematic task. Take the case of the attitude or inner sentiment. The question is how this can be independently characterized. The philosopher John McDowell considers the analogous case of giving a projective account of judgments about what is funny, based on our responses.

But what exactly is it that we are to conceive as projected on to the world so as to give rise to our idea that things are funny? "An inclination to laugh" is not a satisfactory answer; projecting an inclination to laugh would not necessarily yield an apparent instance of the comic, because laughter can signal, for instance, embarrassment just as well as amusement. Perhaps the right response cannot be identified except as amusement; and perhaps amusement cannot be understood except as finding something comic.... But if it is correct, there is serious question whether we can really explain the idea of something's being comic as a projection of that response ... [as] there is no self-contained prior fact of our subjective lives that could enter into a projective account of the relevant way of thinking. ... No doubt the propensity to laugh is in some sense a selfcontained prior psychological fact. But differentiating some exercises of that unspecific propensity as cases of amusement is something we have to learn ... and this learning is indistinguishable from coming to find some things comic. (McDowell 1998, 158)

The implication of the example is this. If moral reactions are to be explained as the projection onto the world of sentiments, it had better be possible to characterize those 
sentiments other than in terms of reactions to worldly features. In the case of comedy, this seems impossible. Moral reactions seem even harder to characterize in terms independent of reactions to worldly but moral features. There is a complementary difficulty. The inner sentiment is supposed to be prompted by genuine, but value-free, features of the external world. This raises the question: What kind of pattern is there, expressible in value-free terms, that prompts the inner sentiments? What, for example, do all cruel actions have in common except for being cruel? Again, a two-factor explanation needs to decompose a moral reaction into two independent factors: a genuine but value-free pattern in the outer world and inner sentiments also characterized other than as a reaction to evaluative features of the world. But neither factor seems to be describable independent of the other.

Subjectivism about values cannot be defeated either by pointing out its prima facie implausibility or even pointing out its deeper explanatory difficulties. But these factors do suggest that suspicion about realism about values may well be misplaced.

\section{The Uncodifiability of Values}

Rather than claiming that values are subjective, however, it is possible to make a distinct claim and still preserve much of the framework for value judgments summarized. This is the claim that value judgments cannot codified: exhaustively summarized by or in principles. The claim that value judgments cannot be codified is again the sort of claim that cannot be given a watertight argument. But a practical argument can be offered against the opposing viewprinciplism-and thus indirectly in favor of particularism.

The familiar role for principles in medical ethics is to guide judgments. Beauchamp and Childress introduce the Four Principles primarily as a tool to offer guidance for medical ethics. They say "These principles can ... function as guidelines for professional ethics" $(2001,12)$ This is an epistemological use for principles. But, according to principlism, ethical principles have to fulfill a second role as well. As well as guiding moral judgments, they set the standard of correctness and incorrectness for those judgments: They discipline those judgments. But this raises a substantial challenge. If the principles discipline judgments, then they should meet two constraints: They should give the right sort of guidance to resemble moral principles and they should be consistent. The problem is that these two constraints pull in different directions. A single, universal principle such as Kant's categorical imperative can be self-consistent, but it does not seem to capture the whole of moral reasoning and thus does not seem, in itself, either to guide or even to discipline judgment. Beauchamp and Childress argue that the only realistic alternative approach is to accept that there are a number of principles that govern moral judgment (Beauchamp and Childress 2001). As they realize, however, such principles can conflict. But if they are to serve the role of disciplining moral judgments, conflict is more than just an epistemological complexity. It threatens the idea that all that makes a moral judgment correct or incorrect is accord with a set of principles. This threatens the underpinnings of principlism.

If principlism fails, however, something else is needed to explain what disciplines value judgments. The alternative, particularism, takes it that rather than thinking that a particular situation merely prompts a balancing of conflicting principles, which themselves discipline a judgment, one should think that the aim of the judgment is just to get the situation itself right. According to particularism, the situation itself contains evaluative features-valuesand ethical judgment aims to describe these.

There are, of course, a number of potential objections to a particularist view of ethical judgment. It requires accepting, for example, that the world itself is partly made up of features that can only be understood from a particular, evaluative standpoint, and that appreciation of these same features can play a role in motivating action without an additional desire (contrary to the long-standing view of the practical syllogism as containing 
beliefs and desires). These objections can, however, be addressed (see, for example, McDowell 1998, 50-73, 131-50; summarized in Thornton 2004, 63-99). Thus, in the face of the grave difficulties of principlism, particularism is a viable alternative, albeit one that also needs refinement.

What matters in this paper are the implications for the codification of judgment. Principlism is the view that judgments can be codified. But there are reasons to doubt its plausibility. This suggests that VBP is at heart a kind of judgment aimed at individuals and particular cases. If so, it can usefully be compared with Kant's concept of reflective judgment which also aimed at particular cases.

\section{Clinical Judgment as Reflective Judgment}

I have suggested that VBP should be understood as a response to the uncodifiability of value judgments and the need to reflect the nature and details of individuals and their particular circumstances. If so then it shares the challenges for clinical judgment in general. In the second half of this paper I set out the underlying problem of how judgment can be aimed at individuals by sketching Kant's distinction between reflective and determinate judgment. I outline the challenge faced by three models of clinical judgment: idiographic understanding, empathy and tacit knowledge. The longer term project of clarifying these will shed light more generally on clinical judgment and hence the role also of VBP.

Consider the distinction that Kant draws between determinate and reflective judgment. He says:

If the universal (the rule, principle, law) is given, then judgment, which subsumes the particular under it, is determinate... . But if only the particular is given and judgment has to find the universal for it, then this power is merely reflective. (Kant 1987, 18) At the risk of riding roughshod over historical nicety, the contrast suggested is between an essentially general judgment-akin to a deductive inference-and a nondeductive particular or singular judgment. Determinate judgment appears, like deductive inference, to be relatively unproblematic. If, for example, one believes that

1. all men are mortal; and

\section{Socrates is a man;}

then it is rational to infer that:

\section{Socrates is mortal.}

One reason this can seem unproblematic is the following thought. If one has accepted premises 1 and 2 then one has, ipso facto, already accepted premise 3. To accept that all men are mortal is to accept that Tom, Dick, Harry, and Socrates are mortal. So given 1 and 2, then 3 is no step at all. Furthermore, some central forms of deductive judgment, at least, can be codified using Frege's logical notation. Given the codification, one can inspect the form of a deductive inference to determine whether true premises could ever lead to a false conclusion. (In fact, neither of these reasons for taking deduction, and thus determinate judgment, is quite so straightforward. For the moment, however, the perceived relative straight forward nature of determinate judgment is what matters.)

By contrast, for what Kant calls 'reflective' judgment, there is a principled problem in how to get from the level of individuals to the level of generalities, or how to get from brute things to the concepts that apply to them. That is not a matter of deduction. To move from the particular to the general is somehow to gain information, not to deploy it. Reflective judgment thus calls for some sort of philosophical account, which is part of the aim of Kant's Critique of Judgement (Kant 1987). 
Against the background assumption that determinate judgment, like deductive inference, is algorithmic and unproblematic, other forms of one-off or particular judgment look problematic. Because clinical judgment has to respond to individuals, it seems to inherit this aspect. Thus, by examining models of particular judgments, light can be shed on clinical judgment. I mention three kinds of nondeterminate judgment worthy of further investigation before commenting on the initial distinction and reflective judgment proper. The three are idiographic judgment, empathy, and tacit knowledge.

Idiographic judgment, like reflective judgment is defined in opposition to a (conception of a) general form of judgment. In this case the general conception is called 'nomothetic' because it concerns laws of nature (nomos in Greek). The inventor of the term 'idiographic,' the neoKantian philosopher Wilhelm Windelband, defines it in this passage:

In their quest for knowledge of reality, the empirical sciences either seek the general in the form of the law of nature or the particular in the form of the historically defined structure. On the one hand, they are concerned with the form which invariably remains constant. On the other hand, they are concerned with the unique, immanently defined content of the real event. The former disciplines are nomological sciences. The latter disciplines are sciences of process or sciences of the event. The nomological sciences are concerned with what is invariably the case. The sciences of process are concerned with what was once the case. If I may be permitted to introduce some new technical terms, scientific thought is nomothetic in the former case and idiographic in the latter case. (Windelband 1980, 175-6)

Idiographic judgment looks to be tailored to addressing the nature of individuals. Whereas nomothetic judgments subsume individuals under general kinds, idiographic judgments are supposed to be directed at 'the uniqueness and incomparability of their object' (Windelband $1980,182)$. For that reason, it has been an important concept in recent discussion of psychiatry, notably the WPA's Institutional Program on Psychiatry for the Person. If psychiatry is aimed at understanding individuals, it might seem that a form of one-off or singular judgment is the perfect vehicle to do that. There are, however, reasons to be suspicious of idiographic judgment. The idea of a form of judgment that eschews generalized conceptual elements in its efforts to track the nature of individual subjects smacks of what Wilfrid Sellars describes as the Myth of the Given (Sellars 1997). The worry is that the very idea of one-off or singular (in this sense) judgment is impossible. There is thus need for further investigation of idiographic judgment and whether its supposed role in psychiatry could be played by something else, such as narrative judgment. (For an initial discussion, see Thornton [2008].)

Empathy is another form of judgment tied to understanding the nature of individuals.

According to Karl Jaspers, empathy lies at the heart of psychological psychiatric understanding. Whereas the rational understanding is only an aid to psychology, empathic understanding is psychology itself. (Jaspers 1913/1974, 83)

Jaspers's view of empathy puts significant weight on the role of fellow feeling. Rather than deploying a codified and context free form of judgment, Jasperian empathy is mediated by psychological aspects of the empathic judge him or herself. Judgment is made possible by the fact that he or she shares common mental attributes with the person whom she or he aims to understand. Subjective symptoms cannot be perceived by the sense organs, but have to be grasped by transferring oneself, so to say, into the other individual's psyche; that is, by empathy. They can only become an inner reality for the observer by his participating in the other person's experiences, not by any intellectual effort. (Jaspers 1912/1968, 1313) 
Empathy thus seems to place particularly substantial constraints on those who aim to make judgments. This contrasts with the idea of placing no constraints on the nature of the judging subject and, as a consequence, putting the burden onto a general 'theory of mind,' which can be deployed by anyone. But this idea raises questions of whether a shared psychology is a necessary feature for empathic understanding or whether it is a contingent and convenient heuristic or short cut for similarly minded agents. Is empathy genuinely distinct as a form of judgment?

Tacit knowledge looks to be another instance of a contrast with determinate judgment. Whereas tacit knowledge need not be one-off (riding a bike or determining the gender of a chicken are general abilities; they apply to lots of bikes and chickens), its application is not a matter of explicit derivation from principles. (Some knowledge that can be tacitly known can also be known explicitly. It can be codified in principles and deployed as a theoretical knowledge. Some, arguably, is essentially tacit.) Thus, it is not, like determinate judgment, a matter of derivation from a universal concept. This conception of knowledge raises a number of questions. I will flag two.

First, if tacit knowledge is not governed by explicit principles, in what sense can it be correct or incorrect, assessed, or evaluated? The sociologist of knowledge Harry Collins assumed that such assessment is at least problematic. He says: "Experimental ability has the character of a skill that can be acquired and developed with practice. Like a skill it cannot be fully explicated or absolutely established" (Collins 1985, 73). Collins appears to assume that what is not explicitly codified cannot be explicated or established either. But this depends on assuming significance for the contrast between what can be codified and what not which, as I will mention below, can be questioned. Second, because tacit knowledge is not explicitly governed by principles, can it be conceptually informed? It seems intuitive to think that the skilled coping that characterizes much tacit knowledge is 'mindless' and thus cannot be regarded as the exercise of a conceptually structured and informed capacity (Dreyfus 2005). If so, that might seem to rule out a role for tacit knowledge in informed clinical judgment. But again, it appears to be a questionable assumption (McDowell 2007). Like the idea that there is a role for idiographic judgment and for empathy in psychiatric clinical judgment, so the idea that it has a tacit dimension raises questions the answers to which will contribute to a fuller understanding of clinical judgment. But having introduced these forms of judgment-which may potentially important for clinical practice-as akin to Kant's concept of reflective judgment, it is worth returning to Kant's distinction. Kant's problem continues to be important for a understanding the nature and difficulties of clinical judgment.

Kant introduces the idea of reflective judgment in the context of this problem. To take a simple, nonmedical example, imagine that someone has judged correctly that there is a cow in front of them on the basis of how things look. If so, various things will follow from that judgment. Cows are relatively slow moving, poor climbers, do not respond to verbal commands, and so forth. Thus it follows that the subject can judge that there is something slow moving, a poor climber, and which will not respond to verbal command before one. But although deriving these judgments from the judgment that it is a cow to the fore is apparently unproblematic, there is a preliminary issue. How, in the face of visual appearances, should the judging subject make the preliminary judgment that there is a cow present?

The problem is that the most natural solution creates a vicious regress. One can imagine that the subject knows a rule which connects a particular kind of appearance with a word. Such a rule would be part of the meaning of the word 'cow'. But the problem is that the rule would have to refer to the range of appearances that justify the application of the word through some general concept, which begs the question of how such a 'visual concept' is justifiably 
applied to any particular cow. Is there a further rule liking a range of appearances to the 'visual concept'?

Kant touches on this problem in the 'schematizm' chapter of the first Critique. The main question of that chapter is how to apply what he calls the 'categories' - the hierarchy of very general and fundamental concepts in Kant's philosophical system - to experience. But he also deals with everyday empirical concepts. The categories present additional problems because as high-level concepts-and unlike empirical concepts-they are 'heterogeneous from empirical intuitions' and an intermediary has to be provided to guide their application. Things are not as complicated in empirical cases. Nevertheless, even here Kant suggests that an intermediary is needed between concepts and objects:

[I]t is [still] schemata, not images of objects, which underlie our pure sensible concepts. ... The concept of 'dog' signifies a rule according to which my imagination can delineate the figure of a four footed animal in a general manner, without limitation to any single determinate figure such as experience, or any possible image that I can represent in concreto, actually presents. (Kant 1929, 182-3)

This does not answer the problem, however. First, it is not clear what the figure or perhaps image of a 'four-footed animal in general' might be like. Second, for any general schematic figure, the question of what determines that it applies to any particular dog would return. Kant recognizes that this account does not really address the problem, commenting:

$[T]$ his schematism of our understanding, in its application to appearances and their mere form, is an art concealed in the depths of the human soul, whose real modes of activity nature is hardly likely ever to allow us to discover. (Kant 1929, 183)

If an account couched in general terms-such as general rules for applying conceptsmerely replicates the problem, what solution is there? The best hope seems to be to undermine the gap used to set up the problem in the first place between grasping a concept and grasping how it applies to the particular instances (Thornton 2007). In fact, although I have set out the contrast between reflective and determinate judgment to suggest that the latter is relatively unproblematic, there is reason to believe that the contrast is not as great as that. In a nutshell, the central message of Wittgenstein's discussion in the Philosophical Investigations of following a rule-an instance of determinate judgment-is that even deductively applying a general principle requires that a judging subject makes a contribution to the derivation, sees what a relevant similar way of going on would be (Wittgenstein 1953). Even an explication of the rule governing adding 2 which says: the units always go ' 0 , $2,4,6,8,10$, and so on' requires that one can connect that very short symbol to an infinite number of cases written in all sorts of specific ways. Thus the contrast on which Collins relies to suggest that tacit knowledge is capricious is undermined because conceptual judgment itself relies on a tacit ability.

Thus, although at first it might seem that the aspects of clinical judgment that call for further philosophical clarification are quite unusual and specific, in fact, judgment as such presents general philosophical puzzles, which will shed light on clinical judgment.

\section{Conclusions}

I have argued that the account of value judgments implicit in VBP suggests that they are uncodifiable. Value judgments answer to, and are disciplined by, particular cases rather than general principles. This is a substantial and important claim about how judgments of values should inform clinical judgment. 
But, as I have also suggested, this view of the philosophically puzzling nature of value judgments dovetails with work that needs to be done on a number of other forms of particular judgments: idiographic, empathic and tacit. Getting clear on these forms of judgment is a necessary prerequisite for a better understanding of clinical judgment. In fact, however, the very idea of empirical judgment and of the application of deductive principles both call for analysis informed, in part, by attention to the analysis of the problems, at least, initiated by Kant and Wittgenstein.

\section{Bibliography}

Beauchamp, T.L. and Childress, J.F. (2001) Principles of Biomedical Ethics, Oxford: Oxford University Press

Blackburn, S. (2000) Ruling Passions, Oxford: Oxford University Press

Collins, H. (1985) Changing Order: Replication and Induction in Scientific Practice, London: Sage

Dreyfus, H.L. (2005) 'Overcoming the Myth of the Mental: How Philosophers Can Profit from the Phenomenology of Everyday Expertise (APA Pacific Division Presidential Address 2005)' Proceedings and Addresses of the American Philosophical Association 79:2

Fulford, K.W.M. (1999b) 'Nine variations and a coda on the theme of an evolutionary definition of dysfunction' Journal of Abnormal Psychology 108: 412-420

Fulford, K.W.M. (2004) 'Ten Principles of Values-Based Medicine' in Radden, J. (ed) The Philosophy of Psychiatry: A Companion New York, Oxford University Press: 205 234.

Hume, D. ([1748] 1975) Enquiries Concerning the Human Understanding and Concerning the Principles of Morals Oxford: Clarendon Press

Jaspers, K. ([1912] 1968) 'The phenomenological approach in psychopathology' British Journal of Psychiatry 114: 1313-1323

Jaspers, K. ([1913] 1974) 'Causal and "Meaningful” Connections between Life History and Psychosis', (trans. J.Hoenig) in Hirsch, S.R., and Shepherd, M. (eds.) Themes and Variations in European Psychiatry, Bristol: Wright: 80-93

Kant, I. (1929) Critique of pure reason London: Macmillan

Kant, I. (1987) Critique of judgment Indianapolis: Hackett

Mackie, J.L. (1977) Ethics: inventing right and wrong, Harmondsworth: Penguin

McDowell, J. (1998) Mind Value and Reality, Cambridge, Mass.: Harvard University Press

McDowell, J. (2007) 'What myth?' Inquiry 50: 338-51

Thornton, T. (2000) 'Mental Illness and Reductionism: Can Functions be Naturalized?' Philosophy, Psychiatry and Psychology 7: 67-76

Thornton, T. (2004) John McDowell, Chesham: Acumen

Thornton, T. (2007) 'An aesthetic grounding for the role of concepts in experience in Kant, Wittgenstein and McDowell?' Forum Philosophicum 12: 227-45

Thornton, T. (forthcoming 2008) 'Should comprehensive diagnosis include idiographic understanding?' Medicine, Health Care and Philosophy

Wakefield, J.C. (1999) Mental disorder as a black box essentialist concept. Journal of Abnormal Psychology 108: 465-472

Windelband, W. (1980) 'History and natural science' History and Theory \& Psychology 19: 169-85

Wittgenstein, L. (1953) Philosophical Investigations, Oxford: Blackwell 
Woodbridge, K. and Fulford, K.W.M. (2004) Whose Values? A workbook for values-based practice in mental health care, London: Sainsbury Centre for Mental Health

Wright, C. (1992) Truth and Objectivity, Cambridge, Mass.: Harvard University Press 